\title{
Customized interventions improved employees' experience of recovery during the workday
}

\author{
Lina Ejlertsson*, Bodil Heijbel, Annika Brorsson, Margareta Troein and Ingemar H. Andersson \\ Department of Clinical Sciences, Faculty of Medicine, Lund University, Malmö, Sweden
}

Received 20 December 2019

Accepted 17 February 2021

\begin{abstract}
.
BACKGROUND: There is a lack of research regarding factors promoting recovery during the workday and effective interventions.

OBJECTIVE: To evaluate how different intervention activities may impact employees' experiences of recovery at the workplace.

METHODS: Customized intervention activities based on qualitative results and a participatory approach were integrated among the employees at six primary health care centres (PHCCs; $n=166$ ) during one year. Recovery and workplace factors were measured with a questionnaire at the start and end of intervention, and also in a control group (15 PHCCs; $n=328)$. Group differences were tested (Chi-2) and explanatory factors compared by logistic regression models.

RESULTS: The proportion of employees reporting workday recovery increased in the intervention group (19.9\% to $29.1 \%$; $p=0.01)$, whereas the control group showed no significant change. Recovery was explained by self-reflection and reflection with co-workers. After intervention, having influence on work situation, energy-building experience, and opportunity for laughter also contributed significantly to recovery.

CONCLUSIONS: The results contribute to work recovery research by confirming that a customized intervention may have an impact on employees' recovery experiences. The study showed that considering the factors of reflection, influence, and companionship can positively impact workplace recovery.
\end{abstract}

Keywords: Work, occupational health, primary health care

\section{Introduction}

Since most people spend a considerable share of their lifetime at work, the workplace is an important setting to promote health and well-being. Job-related fatigue is a critical indicator of overall employee well-being [1], and can be the effect of high work pressure, a poor physical environment, and emotionally demanding interactions at work [2]. Overall, the workplace can be a challenging environment that requires employees to use their energy and

\footnotetext{
*Address for correspondence: Lina Ejlertsson, Department of Clinical Sciences, Faculty of Medicine, Lund University, Jan Waldenströms gata 35, 214 28, Malmö, Sweden. Tel.: +4673204 5580; E-mail: lina.ejlertsson@med.lu.se.
}

personal resources to perform effectively [3]. Drained energy levels and depleted resources need to be recovered in order to function well and stay healthy [4]. Insufficient recovery has been associated with health problems, such as emotional exhaustion, reduced life satisfaction, burnout, and sleep disturbance [5-7]. Work recovery research has focused mainly on employees' time outside of the workday, e.g., during evenings, weekends, and vacations, which has been shown to reduce stress and exhaustion; and on a positive note, it increases employee job performance and well-being [8].

Recovery during the workday has received far less attention, a paradox given that recovery is a process that occurs throughout the day [9]. A recent study reported that recovery is the most important factor 
associated with employees' self-rated health [10]. In the last couple of years, within-day recovery in the form of work breaks has gained some research attention [e.g. 11-13]. Work breaks includes scheduled time away from work tasks such as lunch and coffee breaks, as well as more informal shorter breaks between task episodes, i.e., micro-breaks. One study showed that low levels of autonomy during lunch breaks had negative consequences for well-being [13]. The researchers suggested that the opportunity for employees to decide by themselves how to utilize their breaks could be as important as what they do during the break. There have been studies examining different types of lunch break activities. For example, relaxation through progressive muscle relaxation was shown to reduce employee strain states (emotional, mental, motivational, and physical) over time [14] and significantly decrease sleepiness [15]. Sianoja et al. [16] showed that there is a connection between relaxation exercises during lunchtime and better concentration in the afternoon, as well as lower levels of fatigue. These health outcomes were also associated with taking walks in the park at lunchtime, via enjoyment as an underlying mechanism. Brown et al. [17] investigated the effect of physical activity during lunch breaks, either in a natural or in a built environment. The study showed that self-reported mental health improved for the nature walking group, but not for the group in the built environment or for the control group. Concerning micro-breaks during the workday, the existing literature presents numerous health benefits. Zacher, Brailsford and Parker [18] suggested that microbreaks are positively related to feeling energetic, while another study reported that engaging in microbreaks in the afternoon reduced negative effects of work demands at the end of the workday [12]. Also, employees' daily work engagement was shown to be improved by taking self-initiated short breaks in the afternoon [19]. Similar results were presented by Kim, Park and Headrick [20], where temporary and self-selected recovery experiences had a positive effect on the replenishment of personal resources and strengthened employees' daily work performance. In an ongoing project, of which the current study is a part, health care employees were interviewed about the concept of recovery during the workday. Three main categories of importance were found: variation, companionship, and manageability [21].

A more profound understanding of recovery processes during the workday would be valuable when promoting a healthy and sustainable working life.
This study aimed to evaluate an intervention of different forms of recovery activities in daily work, based on variation, companionship, and manageability. The following research questions were proposed: Did the intervention have any effect on the employees' perceived recovery during the workday? If so, which explanatory factors were most important?

\section{Method}

\subsection{Design}

An intervention aiming at increasing primary health care employees' recovery experiences during the workday, was implemented during the course of one year. An initial cross-sectional questionnaire study was made in two non-randomized groups of primary health care centres (PHCCs), followed by the intervention which was administered to one of the groups. For the second group, their ordinary workdays remained unchanged during the intervention year. Evaluation was performed by repeating the questionnaire study in both groups after the intervention phase.

\subsection{Setting and participants}

This study is part of a larger project exploring recovery during the workday, directed to the primary health care employees of one health care district in southern Sweden. After information about the study was given to all PHCCs, 21 centres agreed to participate. Among those which had shown an interest in taking part as an intervention group, a selection was made to ensure that urban and rural, as well as public and private, PHCCs were included. Consideration was also given to the results of a previous questionnaire study at the same centres about positive work factors [10], and centres with both high and low scores on experienced recovery were therefore included. Six PHCCs constituted the intervention group and the remaining 15 acted as a control group. The total sample (Table 1) included all employees of different professional groups: nurses (registered nurse, assistant nurse), paramedical staff (psychologists, counsellors, occupational therapists, physiotherapists, dieticians), physicians, and administrative staff (such as medical secretaries and receptionists). Staff on long-term sick leave or parental leave were excluded, as well as all the managers and owners of the PHCCs. 
Table 1

Proportion (\%) of respondents by sex, age, profession and working time

\begin{tabular}{lccccc}
\hline & \multicolumn{2}{c}{2017} & & \multicolumn{2}{c}{2018} \\
\cline { 2 - 3 } \cline { 5 - 6 } & $\begin{array}{c}\text { Intervention } \\
\text { group } \\
n=156-157\end{array}$ & $\begin{array}{c}\text { Control } \\
\text { group } \\
n=275-276\end{array}$ & & $\begin{array}{c}\text { Intervention } \\
\text { group } \\
n=151-154\end{array}$ & $\begin{array}{c}\text { Control } \\
\text { group }\end{array}$ \\
& & & & & $n=277$ \\
\hline Sex & 85.4 & 88.4 & & 84.2 & 88.1 \\
Women & 14.6 & 11.6 & & 15.1 & 11.9 \\
Men & 0.0 & 0.0 & & 0.7 & 0.0 \\
Unspecified & 18.5 & 13.4 & & 14.5 & 16.6 \\
Age & 51.0 & 55.8 & & 52.0 & 56.7 \\
34 years and younger & 30.6 & 30.8 & & 33.6 & 26.7 \\
35-54 years & & & & \\
55 years and older & 45.2 & 48.2 & & 44.4 & 53.1 \\
Profession & 17.8 & 17.8 & & 17.2 & 13.4 \\
Nurse & 18.5 & 13.8 & & 19.2 & 14.1 \\
Paramedical staff & 18.5 & 20.3 & & 19.2 & 19.5 \\
Physician & & & & \\
Administrative staff & 6.4 & 9.8 & & 6.0 & 5.4 \\
Working time* & 34.0 & 24.7 & & 26.5 & 23.1 \\
1-50\% & 59.6 & 65.5 & 67.5 & 71.5 \\
51-80\% & & & & & \\
81-100\% & &
\end{tabular}

* $100 \%$ working time corresponds to 40 hours/week.

\subsection{Intervention}

The intervention was built on the previous qualitative study identifying the concept of recovery during the workday, where three areas of importance emerged: variation, companionship, and manageability [21]. The intervention study had a participatory approach [22], where the participants were involved to a varying degree throughout the process. Before intervention start-up, the research group visited the six intervention PHCCs for an introductory meeting with the whole employee groups. The results from the initial study were presented, together with current recovery research and evidence-based suggestions on recovery activities. Each of the participating centres were then asked to form a separate inspiration group, consisting of 3-6 employees from different professional groups. The inspiration groups, together with the first author (L.E.), were responsible for creating and executing ideas about how recovery could be integrated into their daily work. This resulted in six customized recovery models being created, based on variation, companionship, and manageability together with the participants' needs, wishes, and abilities. Established methods for decreasing workrelated fatigue and stress, combined with increasing well-being and recovery, were also considered. The different recovery activities being offered could either be done individually, together with some co-workers, or with the whole employee group. Each employee made a personal decision on which recovery they wanted to perform during the year of the intervention. Examples of recovery activities were micro-pauses in the form of deep breathing or relaxation exercises, lunch break walks, group reflection sessions, notice boards with positive messages, joint morning meetings, music in the breakroom, etc. (see Table 2 for complete list of activities).

At intervention start-up, the research group arranged a gathering at each of the participating centres, where the intervention plan was presented and discussed with the whole employee group present. As the previous study [21] indicated the importance of companionship, a team building activity was performed in an attempt to encourage a positive and joint intervention beginning. During the intervention phase, all inspiration groups had regular meetings during working hours for planning and evaluation of the project. If requested, L.E. attended these meetings to support them. A contact person from each inspiration group also had regular contact with the research group via email and phone, for updates, brainstorming, getting useful materials sent out, etc. The employees at the participating centres could influence and evaluate the recovery activities throughout the intervention phase, by communicating with members of the inspiration group or leaving a note in an anonymous suggestion box. Additionally, once a month during the one-year intervention the whole employee group was given time to reflect on the project at workplace meetings, making joint decisions on how to move forward. At half-time, an inspirational day for all members 
Table 2

Number of intervention centres (ICs), in descending order, that integrated the different forms of recovery activities into daily work

\begin{tabular}{|c|c|c|c|}
\hline $\begin{array}{l}\text { Recovery activities done } \\
\text { individually or together with } \\
\text { co-workers }\end{array}$ & No. of ICs & $\begin{array}{l}\text { Recovery activities together with } \\
\text { the whole employee group }\end{array}$ & No. of ICs \\
\hline Deep breathing exercises & 6 & $\begin{array}{l}\text { Recovery reminders in the form of } \\
\text { coloured stickers around the centre }\end{array}$ & 6 \\
\hline Relaxation exercises & 6 & Monthly recovery reflection & 6 \\
\hline Stretching exercises & 6 & Notice board with positive messages & 6 \\
\hline Access to relaxation room & 3 & Team building activities & 6 \\
\hline $\begin{array}{l}\text { Interprofessional reflection group } \\
\text { meetings }\end{array}$ & 3 & Morning meetings & 5 \\
\hline Access to gym & 2 & Organized after-work activities & 5 \\
\hline Lunch break walks & 2 & Joint physical activity exercises & 4 \\
\hline Mail with mindfulness exercises & 1 & $\begin{array}{l}\text { Concept discussions (e.g. manageability, } \\
\text { influence, companionship, feedback) }\end{array}$ & 4 \\
\hline \multirow{13}{*}{$\begin{array}{l}\text { Brief positive messages } \\
\text { on toilet door }\end{array}$} & 1 & Weekly positivity letter from manager & 4 \\
\hline & & Mindfulness sessions & 3 \\
\hline & & Joint breakfasts & 3 \\
\hline & & Workplace development day & 3 \\
\hline & & Changes in the physical environment & 2 \\
\hline & & Management team & 2 \\
\hline & & Music in the break room & 2 \\
\hline & & Suggestion box for recovery ideas & 2 \\
\hline & & Reflection sessions & 1 \\
\hline & & Breakroom as a work-free zone & 1 \\
\hline & & Step counter contest & 1 \\
\hline & & Medical yoga therapy & 1 \\
\hline & & Basic body awareness therapy & 1 \\
\hline
\end{tabular}

of the six inspiration groups was held. This gathering was an opportunity to increase their knowledge base further, by L.E. giving an update on current research in the work recovery area. Also, the participants could exchange experiences and ideas, which they did through an open discussion on the opportunities and challenges they had faced along the way. This included helping each other with problem solving between workplaces. At intervention ending, a closing reflection session on intervention experiences (lead by the research group) was performed at each of the six PHCCs with the whole employee group present.

\subsection{Questionnaire}

At the intervention start-up (autumn 2017) and ending (autumn 2018) all participants, both intervention group and control group, responded to a questionnaire. The questionnaire had a salutogenic, i.e. positive, perspective [23] and covered recovery, health, and working conditions. It consisted of 12 main question areas, with a total of 73 items. The majority of the questions were developed through analyses of eight focus group interviews in some of the participating PHCCs [21]. The remaining questions came from a previous study on salutogenic work experiences [10].

Questions on age, sex, profession, and employment rate were included in the questionnaire. For most of the questions, a symmetrical Likert-type scale was used, where the respondents specified their level of agreement or disagreement. The statements were positively phrased, with six response alternatives ranging from totally agree (6) to totally disagree (1). In two of the question groups, a semantic differential with six steps was used.

Content validity was addressed by subject matter experts, who declared that the items in the questionnaire reflected the knowledge base. Also, a pilot study was made to improve the face validity of the study. L.E. asked ten primary health care professionals, not participating in the main study, to complete the questionnaire with the use of the method "thinkaloud interviewing" [24] - that is, commenting on the understanding of, and their responses to, the questions while completing the questionnaire. This resulted in some minor changes.

The questionnaires were distributed in person to all participating centres, both at the start-up and one 
year later at the end of the intervention. This was done either at work group meetings, where the employees completed the questionnaire on the spot, or handed out by the managers. The employees then individually and anonymously sent in the questionnaire by mail in a prepaid envelope. This also applied to those who were absent from the work group meetings. To maintain confidentiality, a reminder was sent to the managers who then forwarded it to all the employees.

\subsection{Analysis}

The bivariate relationship between the experience of recovery and intervention/control group, before and after the intervention, was studied. The variable on "recovery during the workday" was divided into three groups: agreeing (5-6), neutral (3-4) and disagreeing (1-2). The significance was controlled by the chi-squared test.

Two multivariate logistic regression models were used to explore the changes in variables affecting the experience of recovery during the workday in the intervention group, before and after the intervention. In total, 10 single statements (Table 3 ) were included in the analyses, which were primarily chosen on empirical grounds, i.e. based on the previous results on factors important to recovery during the workday, where three areas were in focus: variation, companionship, and manageability [21]. The variables were also tested bivariately, with an inclusion criterion of a $p$-value lower than 0.2 . To be able to see the positive extreme, the variables were dichotomized: 5-6 (agreeing) in one group and 1-4 (neutral or disagreeing) in the other. The statements were accompanied by the construct of "energy-building experience" [25], which defines an individual who gave positive responses (4-6) to both of the following questions: $I$ feel that my job gives me new energy and I feel that the energy I get from my job exceeds the energy I lose.

All statistical analyses were carried out using SPSS 25 and the level of significance was set at $p<0.05$.

\subsection{Ethical considerations}

The study was approved by the Regional Ethical Review Board in Lund (2015/490). All participants were given oral and/or written information about the purpose of the study, and the confidentiality of their responses in the questionnaire. By responding, the participants gave their consent to participate. They were also informed that participation was voluntary and that they had the right to withdraw from the study if desired.

\section{Results}

The response rate was $88 \%(n=433 / 494)$ at the start-up in 2017 , and $83 \%(n=431 / 518)$ at the end of the intervention. The majority of the respondents were women, the largest occupational group was nurses, and most of the respondents were between

Table 3

Description of variables used in the analyses

\begin{tabular}{|c|c|c|c|}
\hline Items & $\begin{array}{c}\text { No. of } \\
\text { questions }\end{array}$ & Scale type & Statements \\
\hline Self-reflection & 1 & Likert-type scale & I have time on my own to reflect on work \\
\hline Reflection with co-workers & 1 & Likert-type scale & $\begin{array}{l}\text { I often have a chance for reflection together } \\
\text { with my workmates }\end{array}$ \\
\hline Laughing & 1 & Likert-type scale & I have opportunities to laugh \\
\hline $\begin{array}{l}\text { Satisfied with own work } \\
\text { effort }\end{array}$ & 1 & Likert-type scale & I feel satisfied with the work I do \\
\hline Influence on work situation & 1 & Likert-type scale & $\begin{array}{l}\text { I have a chance to influence my work } \\
\text { situation }\end{array}$ \\
\hline Feedback from co-workers & 1 & Likert-type scale & $\begin{array}{l}\text { I feel that my workmates give me feedback } \\
\text { on the work I do }\end{array}$ \\
\hline $\begin{array}{l}\text { Appreciation from } \\
\text { co-workers }\end{array}$ & 1 & Likert-type scale & I feel appreciated by my workmates \\
\hline Take a break & 1 & Likert-type scale & I have time to take breaks \\
\hline Positive/negative workplace & 1 & Semantic differential & $\begin{array}{l}\text { Characteristics which reflect my workplace: } \\
\text { positive/negative }\end{array}$ \\
\hline $\begin{array}{l}\text { Recovery during the workday } \\
\text { (dependent variable) }\end{array}$ & 1 & Likert-type scale & $\begin{array}{l}\text { I feel I get time for recovery during the } \\
\text { workday }\end{array}$ \\
\hline Energy-building experience & 2 & Likert-type scale & $\begin{array}{l}\text { I feel that my job gives me new energy, I feel } \\
\text { that the energy I get from my job exceeds } \\
\text { the energy I lose }\end{array}$ \\
\hline
\end{tabular}


Table 4

Proportion $(\%)$ of respondents experiencing "recovery during the workday". Comparison between before (2017) and after (2018) intervention

\begin{tabular}{lccccccc}
\hline & \multicolumn{3}{c}{ Intervention group* } & & \multicolumn{3}{c}{ Control group** $^{*}$} \\
\cline { 2 - 3 } \cline { 6 - 7 } & Agreeing & Neutral & Disagreeing & & Agreeing & Neutral & Disagreeing \\
\hline 2017 & 19.9 & 39.1 & 41.0 & & 22.9 & 44.0 & 33.1 \\
2018 & 29.1 & 45.7 & 25.2 & & 26.0 & 46.2 & 27.8 \\
\hline
\end{tabular}

${ }^{*}$ Chi-square $=9.294, \mathrm{df}=2, p=0.01 .{ }^{* *}$ Chi-square $=1.956, \mathrm{df}=2, p=0.38$.

35 and 54 years of age (Table 1). These proportions apply to both groups (intervention and control), both years.

After the intervention, the intervention group (i.e. the six participating PHCCs seen as one group) showed a significant $(p=0.01)$ improvement in experiencing recovery during the workday, when compared to before the intervention start-up (Table 4). There was no such difference in the control group (i.e. the remaining 15 PHCCs) $(p=0.38)$. Before the intervention, $19.9 \%$ of the intervention participants had a positive response to the statement I feel I get time for recovery during the workday. After the intervention, this percentage increased to 29.1. Also, the disagreeing group of $41.0 \%$ decreased to $25.2 \%$ after the intervention.

A multivariate logistic regression model (Table 5), with recovery during the workday in the intervention group before the intervention as the dependent variable, showed two significant relationships: selfreflection $(\mathrm{OR}=10.2)$ and reflection with co-workers $(\mathrm{OR}=4.63)$.

Another multivariate logistic regression model (Table 6), with the same independent variables but recovery during the workday in the intervention group after the intervention as the dependent variable, showed that reflection with co-workers had the highest relationship to recovery $(\mathrm{OR}=7.42)$. Also,

Table 5

Results from bivariate analysis and a multivariate logistic regression model with "recovery during the workday" as dependent variable. Data from intervention group $2017(n=156)$, before the intervention. Adjusted by age and sex

\begin{tabular}{|c|c|c|c|c|}
\hline & \multicolumn{2}{|c|}{ Bivariate } & \multicolumn{2}{|c|}{ Multivariate } \\
\hline & OR $(95 \% \mathrm{CI})$ & $p$-value & OR $(95 \% \mathrm{CI})$ & $p$-value \\
\hline Self-reflection & $17.8(6.77-47.0)$ & 0.000 & $10.2(2.29-45.0)$ & 0.002 \\
\hline Reflection with co-workers & $9.78(4.01-23.8)$ & 0.000 & $4.63(1.21-17.7)$ & 0.026 \\
\hline Influence on work situation & $8.09(3.36-19.5)$ & 0.000 & $2.56(0.72-9.10)$ & 0.146 \\
\hline Feedback from co-workers & $7.95(3.03-20.8)$ & 0.000 & $2.91(0.64-13.4)$ & 0.169 \\
\hline Energy-building experience & $7.91(2.83-22.1)$ & 0.000 & $2.34(0.48-11.4)$ & 0.292 \\
\hline Appreciation from co-workers & $3.78(1.08-13.2)$ & 0.038 & $0.37(0.05-2.54)$ & 0.311 \\
\hline Satisfied with own work effort & $2.73(0.98-7.61)$ & 0.055 & $0.66(0.13-3.38)$ & 0.613 \\
\hline Positive/negative workplace & $4.35(1.44-13.2)$ & 0.009 & $1.39(0.32-6.07)$ & 0.663 \\
\hline Take a break & $6.83(2.61-17.9)$ & 0.000 & $1.32(0.31-5.64)$ & 0.711 \\
\hline Laughing & $6.10(1.76-21.2)$ & 0.004 & $1.06(0.19-5.94)$ & 0.951 \\
\hline
\end{tabular}

${ }^{*}$ Hosmer and Lemeshow test $p=0.136 .{ }^{* *}$ Nagelkerke R Square 0.571 .

Table 6

Results from one bivariate and one multivariate logistic regression model with "recovery during the workday" as dependent variable. Data from intervention group $2018(n=151)$, after the intervention. Adjusted by age and sex

\begin{tabular}{|c|c|c|c|c|}
\hline & \multicolumn{2}{|c|}{ Bivariate } & \multicolumn{2}{|c|}{ Multivariate } \\
\hline & OR $(95 \% \mathrm{CI})$ & $P$ & OR $(95 \% \mathrm{CI})$ & $P$ \\
\hline Self-reflection & $13.9(5.83-33.0)$ & 0.000 & $3.70(1.09-12.6)$ & 0.036 \\
\hline Reflection with co-workers & $9.27(4.15-20.7)$ & 0.000 & $7.42(2.18-25.2)$ & 0.001 \\
\hline Influence on work situation & $7.56(3.41-16.8)$ & 0.000 & $3.76(1.18-12.0)$ & 0.025 \\
\hline Feedback from co-workers & $2.82(1.31-6.06)$ & 0.008 & $0.42(0.11-1.59)$ & 0.204 \\
\hline Energy-building experience & $7.60(3.13-18.5)$ & 0.000 & $4.24(1.14-15.8)$ & 0.031 \\
\hline Appreciation from co-workers & $1.96(0.74-5.16)$ & 0.176 & $0.29(0.03-2.49)$ & 0.259 \\
\hline Satisfied with own work effort & $6.74(1.95-23.3)$ & 0.003 & $3.17(0.58-17.3)$ & 0.184 \\
\hline Positive/negative workplace & $8.29(1.89-36.4)$ & 0.005 & $0.76(0.09-6.10)$ & 0.793 \\
\hline Take a break & $4.19(1.84-9.58)$ & 0.001 & $1.62(0.44-5.98)$ & 0.472 \\
\hline Laughing & $26.7(3.54-201)$ & 0.001 & $12.8(1.02-162)$ & 0.049 \\
\hline
\end{tabular}

*Hosmer and Lemeshow test $p=0.367 .{ }^{* *}$ Nagelkerke R Square 0.610 . 
having influence on work situation $(\mathrm{OR}=3.76)$, an energy-building experience $(\mathrm{OR}=4.24)$, the possibility of self-reflection $(\mathrm{OR}=3.70)$ and the opportunity for laughter ( $\mathrm{OR}=12.8)$ were significant predictors of recovery during the workday. The total model explained $61.0 \%$ of the variance.

\section{Discussion}

The most substantial finding in the current study was the change in experienced recovery during the workday in the intervention group. There was a shift, as a large proportion of those not experiencing recovery before the intervention did so at the end of the intervention. This result leads to the conclusion that the intervention has made an increase in experienced recovery during the workday, since these changes were not found in the control group. Also, the analysis showed a change in significant factors of importance to recovery during the workday, before and after the intervention, which indicates that the intervention has made an impact. Recovery was related to self-reflection and reflection with co-workers both before and after the intervention. However, reflection with co-workers had a considerably higher odds ratio (OR) after the intervention ended, which can be interpreted as a result of the actions taking place at the intervention centres. Having influence on work situation, energy-building experience and opportunity for laughter became explanatory variables after the intervention.

Various forms of recovery activities were integrated into daily work, and the result shows that reflection with co-workers was the most important factor related to recovery during the workday after intervention ended. As a part of the intervention some of the participating centres worked with discussing the concept of reflection, i.e. what it is and how it can be integrated in the daily work. A study exploring communication in primary health care teams found two types of communication for successful teamwork: formal and informal. An example of formal communication was team meetings, where team members could discuss and solve problems [26]. This reflection method was included in the current study, where some of the participating centres implemented regular meetings within their professional group. Brown [26] described informal communication as e.g. "hallway" consultations and chats about patient care. These types of reflection moments are essential to be able to provide the best possible patient care and - as was shown in the current study - create recovery opportunities for the employees. One of the intervention centres tested shared reflection during the coffee break, where anyone who felt the need to reflect on something had the opportunity. Aside from this, all six centres used part of their monthly workplace meeting for joint reflection on experienced recovery. In a study in community health services [27], having reflection groups (especially on ethics) was found to increase professional development and motivation to do a good job. The same study showed that participation had a positive impact on collegial relationships and support, as well as the employees' ability to reflect on their own work efforts in a constructive way.

Taking the time to reflect during the workday has been shown to have other positive effects for the individual. For example, Aronsson [28] emphasized that this would reduce the need to carry work thoughts out of the workplace. Self-reflection had a significant relationship with recovery in the current study, where some of the participants used micro-breaks in between patients to "clear their minds" before seizing the next task. This could be done by taking a deep breath, looking out the window, or listening to their favourite song, depending on how much time they had when needing a moment of self-reflection. Positive work reflection, which means thinking about happy and enjoyable episodes of the ongoing workday, can boost optimism and hope [29] as well as invigorate the employees' recovery process [30]. Similar results were presented by Clauss et al. [31], who found that five minutes of positive work reflection on a daily basis helped the participants to recover from fatigue and exhaustion, which nourished their well-being. Self-reflection could also contribute to professional improvement and individual growth [32].

In this study, another factor important for recovery during the workday was the experience of influence over the work situation. For example, the intervention groups used workplace meetings for discussions, with the goal of making all employees feel seen and heard. Considering the possibility of influence, the term job crafting is often used. Job crafting refers to employee-initiated attempts to have an impact on their job and make physical and cognitive changes to it [33]. Studies revealed that job crafting is positively related to increased work engagement [34], job satisfaction [35], and job autonomy [36]. Autonomy has an important role in replenishing drained energy [37], and studies on lunch break activities have shown that high autonomy (i.e. freedom to decide what to do) 
resulted in increased motivation and concentration at work [11] as well as decreased fatigue at the end of the workday [13]. The employee autonomy was a foundation in this study, mainly by all participants choosing their own recovery activities. At some of the centres in the current study a forum for employee influence, in the form of workplace development days, was arranged. Concept discussions, together with idea generation and participation in decisionmaking regarding the workplace structure were in focus, which is in line with Andruškiene et al. [38], who emphasized that enhancing that kind of influence could affect having a positive work experience. Also, having an influence on your work situation was found to be one of the categories important for recovery during the workday in the initial qualitative study [21].

There is evidence that humour in the workplace can be beneficial for employee health, for example, effects like better immune function [39], enhanced problem-solving skills [40], improved stress management [41] and strengthened relationship with co-workers [42]. When exploring the concept of recovery during the workday in the foregoing qualitative study laughter was found to have an important positive value, which also increased companionship and made the work feel easier [21]. This was confirmed by the current study, where laughter was one of the significant factors associated with recovery. All intervention centres tried team building activities to enhance group cohesion, where laughter was an essential bonus effect. Also, recovery activities like notice boards with positive messages, joint physical exercises, and lunch break walks where the employees could chat about something other than their work promoted a good workplace atmosphere with laughter. A study on nurses [43] showed that those with a humour-oriented character were more likely to be satisfied in their work. Similar results were found in a study by Ghaffari [44], where the participating nurses described how humour is necessary to make the working environment enjoyable. For achieving a healthy work climate, the manager also plays an important role in creating a humorous atmosphere for the employees [45], where they can be filled with positive energy instead of being depleted.

The last significant factor associated with recovery during the workday, after the intervention, was having an energy-building experience. De Bloom, Kinnunen and Korpela [46] have found that the more energy that is left at the end of the workday, the better the recovery process may continue after work. Also, having an energy-building experience at work effect how highly employees rate their health [25]. How to restore as much energy as possible is largely individual, but there is research that gives clues about ways that function. The most common way is to take a break [47], which can be anything from having a cup of coffee to stretching or chatting with a co-worker. Some of which the participants in this intervention study did, referred to as micro-pauses. Steidle et al. [48] found that engaging in short respites (either savouring nature or practising muscle relaxation) helped the employees to preserve their energy levels during the workday. Employees who experience their work as meaningful and enjoyable are prone to reinvest their energy in their work [49], and the same goes for having positive workplace relationships [50]. The concept of relational energy, coined by Owens, Baker, Sumpter, and Cameron [51], suggests that employees who are energized by co-workers have elevated levels of work performance, engagement, and productivity.

\subsection{Methods discussion}

The current study has both strengths and limitations. The high response rate $(88 \%$ at start-up and $83 \%$ at intervention ending) represents a strength of the study, since it is important for drawing valid conclusions in reducing the risk of potential dropout effects on the findings. Several factors may contribute to the low questionnaire dropout, for example the salutogenic perspective, the personal distribution, the anchoring work, the close communication with all managers and owners, and the promise to each PHCC that the results from the questionnaire would be reported back. When distributing a questionnaire, the time of year matters [52]. This was considered in the current study together with the fact that the questionnaire was completed during the same month, consecutive years (before and after the intervention). Moreover, the participating PHCCs implemented various recovery activities which the employees could choose from depending on what suited their characteristics and situation, as part of the participatory approach. According to Lyubomirsky and Layous [53], individuals have different preferences and needs, which makes the activity range in the current study a strength. The use of a control group with prospective follow-up of both groups strengthens the results, even though there is a potential risk with the quasi-experimental study design concerning selection bias. 
The intervention needs to be regarded as one package, consisting of different recovery activities being offered - and used - to a various degree by the participating workplaces and their individual employees. How the intervention process proceeded was mainly due to the different needs, wishes and abilities in the intervention group. Several positive effects of the intervention were shown in this quantitative study. Though, which specific action that led to these results cannot be distinguished because of this study setup.

In terms of potential limitations, there are some other points of concern that should be addressed. The questionnaire was self-constructed based on the results of the previous qualitative study. This lack of extensive validation is a limitation, even though the questions were well-founded and tested in a pilot study. Recovery during workdays is a new research topic and there is a lack of established questionnaires with a salutogenic perspective. The self-construction was therefore considered necessary. Since it consisted of self-report measures based on the foregoing interview study, it can be considered as a limitation due to the risk of information bias. Also, lifestyle factors outside of the workplace which may have an impact on work recovery were not considered. The regression analyses were based on cross-sectional data, which influences the interpretation of causes. For all intervention studies, there may be a risk that some of the positive changes in the intervention group are due to the fact that they were studied rather than to the efforts themselves. The study was conducted in a primary health care setting and the intervention was adapted to these conditions, which warrants some caution in generalizing the current findings to other work contexts. However, the researchers claim that it could be possible to use the results to create customized recovery models in other workplaces.

\section{Conclusion and directions for future research}

We propose that a goal for every employee should be to go home from a day at work not being totally drained. By integrating different forms of recovery into daily work, this study was an attempt to see if that is possible. We found a positive change in recovery experiences after the intervention. It seems that activities focusing on reflection, influence and companionship could be guidelines for individual employees, as well as management, when striving for enhancing workplace recovery. The results in this study could benefit from being supplemented by a qualitative approach, to arrive at a deeper understanding of the intervention and the factors of importance for recovery during the workday.

\section{Acknowledgments}

This work was supported by AFA Insurance, Sweden (grant number 141298).

\section{Conflict of interest}

The authors declare that they have no conflict of interest.

\section{References}

[1] Maslach C, Schaufeli WB, Leiter MP. Job burnout. Annu Rev Psychol. 2001;52:397-422.

[2] Bakker AB, Demerouti E. Job demands-resources theory: Taking stock and looking forward. J Occup Health Psychol. 2017;22(3):273-85.

[3] Meijman TF, Mulder G. Psychological aspects of workload. In: Drenth PJD, Thierry H, de Wolff CJ, editors. Handbook of work and organizational psychology. 2nd ed. Hove: Psychology Press Taylor \& Francis; 1998. P. 5-33.

[4] Sianoja M, Kinnunen U, de Bloom J, Korpela K. Insufficient recovery from job stress as a risk factor for poor health and well-being. In: Hopkins CR, editor. Job Stress: Risk Factors, Health Effects and Coping Strategies. Hauppauge: Nova Science Publishers; 2015;27-48.

[5] Geurts SA, Sonnentag S. Recovery as an explanatory mechanism in the relation between acute stress reactions and chronic health impairment. Scand J Work Environ Health. 2006;32(6):482-92.

[6] Lee FJ, Stewart M, Brown JB. Stress, burnout, and strategies for reducing them: what's the situation among Canadian family physicians? Can Fam Physician. 2008;54(2):234-5.

[7] Rabin S, Shorer Y, Nadav M, Guez J, Hertzanu M, Shiber A. Burnout among general hospital mental health professionals and the salutogenic approach. Isr J Psychiatry Relat Sci. 2011;48(3):175-81.

[8] Demerouti E, Bakker AB, Geurts SAE, Taris TW. Daily recovery from work-related effort during non-work time. Current perspectives on job-stress recovery. Research in occupational stress and well-being. Bingley: JAI Press/Emerald Group Publishing, 2009;85-123.

[9] Sonnentag S, Venz L, Casper A. Advances in recovery research: What have we learned? What should be done next? J Occup Health Psychol. 2017;22(3):365-80.

[10] Ejlertsson L, Heijbel B, Ejlertsson G, Andersson I. Recovery, work-life balance and work experiences important to self-rated health: A questionnaire study on salutogenic work factors among Swedish primary health care employees. Work. 2018;59(1):155-63.

[11] Hunter EM, Wu C. Give me a better break: Choosing workday break activities to maximize resource recovery. J Appl Psychol. 2016;101(2):302-11. 
[12] Kim S, Park Y, Niu QK. Micro-break activities at work to recover from daily work demands. J Organizational Behav. 2017;38(1):28-44.

[13] Trougakos JP, Hideg I, Cheng BH, Beal DJ. Lunch Breaks Unpacked: The Role of Autonomy as a Moderator of Recovery during Lunch. Academy Manag J. 2014;57(2):405-21.

[14] Krajewski J, Wieland R, Sauerland M. Regulating strain states by using the recovery potential of lunch breaks. $\mathrm{J}$ Occup Health Psychol. 2010;15(2):131-9.

[15] Schnieder S, Stappert S, Takahashi M, Fricchione GL, Esch T, Krajewski J. Sustainable Reduction of Sleepiness through Salutogenic Self-Care Procedure in Lunch Breaks: A Pilot Study. Evid Based Complement Alternat Med. 2013;2013:387356.

[16] Sianoja M, Syrek CJ, de Bloom J, Korpela K, Kinnunen U. Enhancing daily well-being at work through lunchtime park walks and relaxation exercises: Recovery experiences as mediators. J Occup Health Psychol. 2018;23(3): 428-42.

[17] Brown DK, Barton JL, Pretty J, Gladwell VF. Walks4Work: assessing the role of the natural environment in a workplace physical activity intervention. Scand J Work Environ Health. 2014;40(4):390-9.

[18] Zacher H, Brailsford HA, Parker SL. Micro-breaks matter: A diary study on the effects of energy management strategies on occupational well-being. J Vocat Behav. 2014;85(3): 287-97.

[19] Kühnel J, Zacher H, de Bloom J, Bledow R. Take a break! Benefits of sleep and short breaks for daily work engagement. European J Work Organizational Psychol. 2016;26(4):481-91.

[20] Kim S, Park Y, Headrick L. Employees' Micro-Break Activities and Job Performance: An Examination of Telemarketing Employees. Academy Manag Proceed. 2015;2015(1).

[21] Ejlertsson L, Heijbel B, Troein M, Brorsson A. Variation, companionship and manageability important for recovery during working hours: A qualitative focus group study. Work. 2018;61(1):149-56.

[22] Ledwith M, Springett J. Participatory practice: Communitybased action for transformative change. Bristol: Policy Press; 2010.

[23] Antonovsky A. Unraveling the mystery of health. How people manage stress and stay well. San Fransisco: Jossey-Bass Inc; 1987.

[24] Charters E. The use of think-aloud methods in qualitative research an introduction to think-aloud methods. Brock Educ: J Educ Research Pract. 2003;12(2).

[25] Ejlertsson L, Heijbel B, Brorsson A, Andersson IH. Is it possible to gain energy at work? A questionnaire study in primary health care. Prim Health Care Res Dev. 2020; 21(e65):1-6.

[26] Brown JB, Lewis L, Ellis K, Stewart M, Freeman TR, Kasperski MJ. Mechanisms for communicating within primary health care teams. Can Fam Physician. 2009; 55(12):1216-22.

[27] Lillemoen L, Pedersen R. Ethics reflection groups in community health services: an evaluation study. BMC Med Ethics. 2015;16:25.

[28] Aronsson G, Astvik W, Gustafsson K. Work conditions, recovery and health: A study among workers within preschool, home care and social work. British J Soc Work. 2013;44(6):1654-72.

[29] Meier LL, Cho E, Dumani S. The effect of positive work reflection during leisure time on affective well-being:
Results from three diary studies. J Organizational Behav. 2016;37(2):255-78

[30] Bono JE, Glomb TM, Shen W, Kim E, Koch AJ. Building Positive Resources: Effects of Positive Events and Positive Reflection on Work Stress and Health. Acad Manag J. 2013;56(6):1601-27.

[31] Clauss E, Hoppe A, O'Shea D, Gonzalez Morales MG, Steidle A, Michel A. Promoting personal resources and reducing exhaustion through positive work reflection among caregivers. J Occup Health Psychol. 2018;23(1):127-40.

[32] Carlson E, Nygren F, Wennick A. Critical Friends: Health Professionals' Experiences of Collegial Feedback in a Clinical Setting. J Contin Educ Health Prof. 2018;38(3):179-83.

[33] Wrzesniewski A, Dutton JE. Crafting a job: Revisioning employees as active crafters of their work. Acad Manag Review. 2001;26(2):179-201.

[34] Vogt K, Hakanen JJ, Brauchli R, Jenny GJ, Bauer GF. The consequences of job crafting: A three-wave study. Euro J Work Organizational Psychol. 2016;25(3):353-62.

[35] Rudolph CW, Katz IM, Lavigne KN, Zacher H. Job crafting: A meta-analysis of relationships with individual differences, job characteristics, and work outcomes. J Vocat Behav. 2017;102:112-38.

[36] Lyons P. The crafting of jobs and individual differences. J Business Psychol. 2008;23(1-2):25-36.

[37] Ryan RM, Deci EL. From ego depletion to vitality: Theory and findings concerning the facilitation of energy available to the self. Soc Person Psychol Compass. 2008;2(2):702-17.

[38] Andruškienè J, Kuzmienė A, Martinkènas A, Jurgutis A, Ejlertsson G, Andersson I. Psychosocial work experiences related to health: A study of Lithuanian hospital employees. Work. 2016;53(3):669-77.

[39] MacDonald LCM. A chuckle a day keeps the doctor away: therapeutic humor \& laughter. Journal of Psychosocial Nursing and Mental Health Services. 2004;42(3):18-25

[40] Holmes J. Making humour work: Creativity on the job. Applied linguistics. 2007;28(4):518-37.

[41] Doosje S, De Goede M, Van Doornen L, Goldstein J. Measurement of occupational humorous coping. Walter de Gruyter GmbH \& Co. KG; 2010.

[42] Cooper C. Elucidating the bonds of workplace humor: A relational process model. Human Relations. 2008;61(8):1087-115.

[43] Wanzer M, Booth-Butterfield M, Booth-Butterfield S. "If we didn't use humor, we'd cry": humorous coping communication in health care settings. J Health Commun. 2005;10(2):105-25

[44] Ghaffari F, Dehghan-Nayeri N, Shali M. Nurses' experiences of humour in clinical settings. Med J Islam Rep Iran. 2015;29:182.

[45] Kroth M, Boverie P, Zondlo J. What Managers Do to Create Healthy Work Environments. J Adult Educ. 2007;36(2): $1-12$.

[46] de Bloom J, Kinnunen U, Korpela K. Recovery processes during and after work. J Occup Environ Med. 2015;57(7):732-42.

[47] Meijman T, Mulder G, Drenth P, Thierry H, de Wolff C. Handbook of work and organizational psychology. Work Psychol. 1998;2.

[48] Steidle A, Gonzalez-Morales MG, Hoppe A, Michel A, O'shea D. Energizing respites from work: a randomized controlled study on respite interventions. Eur J Work Organizational Psychol. 2017;26(5):650-62.

[49] Zeijen ME, Peeters MC, Hakanen JJ. Workaholism versus work engagement and job crafting: What is the role 
of self-management strategies? Hum Resource Manag J. 2018;28(2):357-73.

[50] Fritz C, Lam CF, Spreitzer GM. It's the Little Things That Matter: An Examination of Knowledge Workers' Energy Management. Acad Manag Persp. 2011;25(3):28-39.

[51] Owens BP, Baker WE, Sumpter DM, Cameron KS. Relational energy at work: Implications for job engagement and job performance. J Appl Psychol. 2016;101(1):35-49.
[52] Ejlertsson G. [The questionnaire in practice: a handbook in survey methodology]. Lund: Studentlitteratur; 2019. Swedish.

[53] Lyubomirsky S, Layous K. How Do Simple Positive Activities Increase Well-Being? Curr Direc Psychol Sci. 2013;22(1):57-62. 